\title{
Meta-analysis of Nekton Recovery Following Marsh Restoration in the Northern Gulf of Mexico
}

\author{
Terill A. Hollweg ${ }^{1}$ (D) - Mary C. Christman ${ }^{2} \cdot$ Joshua Lipton $^{1} \cdot$ Bryan P. Wallace ${ }^{3,4} \cdot$ Mary T. Huisenga $^{1,5} \cdot$ Diana R. Lane $^{1}$. \\ Kristopher G. Benson ${ }^{6}$
}

Received: 29 May 2018 / Revised: 29 July 2019 / Accepted: 27 August 2019 / Published online: 30 October 2019

(C) The Author(s) 2019

\begin{abstract}
To investigate regional patterns in marsh recovery following restoration, a meta-analysis of nekton densities at restored and reference marshes in the northern Gulf of Mexico (GOM) was conducted. Results were variable at both restored and reference sites, but general trends with respect to the age of the restored site were observed. Pooled together, mean total nekton density in restored marshes during the first 5 years following restoration was approximately 50\% of reference marsh densities [95\% confidence interval (CI): 26.6-93.0\%]. Mean total nekton density in restored marshes in subsequent years (age of restored sites: 6 to 30 years) was approximately $73 \%$ of reference marsh densities (95\% CI: 46.1-116.1\%). Relative densities of crustaceans in restored marshes tended to be lower than in reference marshes during both the initial 5 years following restoration (mean $=36 \%$; 95\% CI: $16.6-76.7 \%$ ) and in subsequent years (mean $=71 \%$; 95\% CI: 42.7-119.2\%). Mean densities of fish species also tended to be somewhat lower in restored marshes than in reference marshes, but relative densities were highly variable during both the initial 5-year period (mean $=85 \%$; 95\% CI: $33.5-215.3 \%)$ and in subsequent years (mean $=77 \%$; 95\% CI: 39.3-152.7\%). A generally increasing trend in total nekton and total crustacean densities was observed over the first 15 years following restoration; mean densities at restored sites were comparable to paired reference locations by approximately year 13 . Findings from this study indicate that marsh restoration may not consistently result in nekton production similar to that of natural sites, particularly in the earlier years following restoration when baseline ecosystem processes are developing.
\end{abstract}

Keywords Nekton $\cdot$ Marsh restoration $\cdot$ Marsh creation $\cdot$ Recovery $\cdot$ Response ratio $\cdot$ Gulf of Mexico

Communicated by Matthew D. Taylor

Electronic supplementary material The online version of this article (https://doi.org/10.1007/s12237-019-00630-1) contains supplementary material, which is available to authorized users.

Terill A. Hollweg

terill_hollweg@abtassoc.com

1 Abt Associates, 1881 Ninth Street, Suite 201, Boulder, CO 80302, USA

2 MCC Statistical Consulting LLC, 2219 NW 23rd Terrace, Gainesville, FL 32605, USA

3 Conservation Science Partners, Inc., 5 Old Town Square, Suite 205, Fort Collins, CO 80524, USA

4 Nicholas School of the Environment, Duke University Marine Laboratory, 135 DUML Road, Beaufort, NC 28516, USA

5 Present address: SWCA Environmental Consultants, 295 Interlocken Boulevard, Suite 300, Broomfield, CO 80021, USA

6 NOAA Restoration Center, 4700 Avenue U, Building 307, Galveston, TX 77551, USA

\section{Introduction}

The northern Gulf of Mexico (GOM) is home to a network of saline, brackish, intermediate, and freshwater marshes that contain close to $40 \%$ of all the coastal wetlands in the contiguous United States (Dahl and Stedman 2013). These marsh habitats serve as valuable ecological, commercial, recreational, and cultural resources to the GOM. For example, coastal marshes are considered important nursery grounds for many fish and crustacean species (Boesch and Turner 1984; McIvor and Rozas 1996; Beck et al. 2001; Minello et al. 2003). In addition to being key components of the coastal ecosystem, many of the species using coastal habitats are of commercial and recreational value. Over $95 \%$ of commercial fisheries (by weight) in the GOM are composed of estuarine-dependent species (Chambers 1992; Lellis-Dibble et al. 2008). In 2017 alone, US commercial fishers in the GOM landed over 600,000 metric tons of finfish and shellfish, valued at $\$ 856$ million (NMFS 2018). 
Coastal habitats of the northern GOM are experiencing extensive land loss due to a variety of factors, including the engineering of the Mississippi River, storms, subsidence, relative sea level rise, construction of canals for oil and gas development, and urban and rural development (Boesch et al. 1994; Day et al. 2000, 2007; Dahl and Stedman 2013). Between 2004 and 2009, the Gulf States lost an estimated 39,000 ha of saltwater wetlands, with the majority being converted to open-water habitat (Dahl and Stedman 2013). Although prevalent along all five Gulf States, land loss is greatest in Louisiana (Dahl and Stedman 2013), with an average annual loss rate of 4290 ha between 1985 and 2010 (Couvillion et al. 2011).

Given the importance of healthy wetlands to coastal communities and ecosystems (Zedler and Kercher 2005), increased federal and state efforts in the past few decades have focused on coastal habitat restoration in the northern GOM. Numerous restoration plans in the region, including the Gulf of Mexico Regional Ecosystem Restoration Strategy (Gulf Coast Ecosystem Restoration Task Force 2011); the Resources and Ecosystems Sustainability, Tourist Opportunities, and Revived Economies of the Gulf Coast States Act's (RESTORE Act's) Initial Comprehensive Plan (Gulf Coast Ecosystem Restoration Council 2016); the Deepwater Horizon oil spill Final Programmatic Damage Assessment and Restoration Plan (DWH NRDA Trustees 2016); and Louisiana's 2017 Coastal Master Plan (CPRA 2017), have highlighted coastal habitat restoration and conservation as a key focus. In addition, restoration work in the region is underway. The federal Coastal Wetlands Planning, Protection and Restoration Act (CWPPRA) has authorized over 200 projects in Louisiana since its enactment in 1990 (www.lacoast.gov), and marsh terrace projects (consisting of narrow strips of created marsh) have been initiated in southwest Louisiana and southeast Texas (Turner and Streever 2002). Because coastal restoration is a management priority in the northern GOM, restoration planning, siting, implementation, and evaluation must rely on best scientific practices and include information gained from the monitoring and evaluation of previous and ongoing restoration projects.

One of the goals of coastal restoration is to create habitat that supports ecological functions (e.g., species utilization, productivity) equivalent to natural habitats in similar areas. A number of studies support the idea that marsh restoration and creation projects enhance habitat value for fisheries, demonstrated by higher densities or biomass of fish and crustaceans (hereafter referred to collectively as "nekton") in the restored or created marsh compared to open-water sites that are representative of pre-restoration conditions (Rozas and Minello 2001, 2007; Thom et al. 2004; La Peyre et al. 2007; Merino et al. 2010; Hollweg et al. 2019). For example, marsh terraces are hypothesized to support relatively high fish populations (Rozas et al. 2005; Rozas and Minello 2007) because they have a high marsh edge to area ratio, and nekton densities have been observed to be highest at this transition between marsh and open water (Baltz et al. 1993; Peterson and Turner 1994; Minello and Rozas 2002; Minello et al. 2008; Hollweg et al. 2019). However, questions related to the relative function of restored marsh habitats to natural marsh habitats remain (Streever 2000; Zedler 2000; Callaway 2005), such as habitat provisioning for fish and crustaceans. Some studies in the northern GOM have found comparable densities of nekton in restored and reference marshes (e.g., Thom et al. 2004; La Peyre et al. 2007; Rozas and Minello 2007; Llewellyn and La Peyre 2011; La Peyre and Gordon 2012), while others have observed greater densities in reference marshes (e.g., Minello and Zimmerman 1992; Minello and Webb 1997; Rozas and Minello 2001; Zeug et al. 2007). Other measures of habitat function also exhibit dissimilarity between restored and reference sites, such as nekton community composition (Thom et al. 2004; La Peyre et al. 2007; Zeug et al. 2007), fish health (La Peyre et al. 2007), population size structure (Zeug et al. 2007), and food web structure (Llewellyn and La Peyre 2011).

While the goal of many coastal habitat restoration projects is to achieve functional equivalency to reference sites, evaluation of restoration success is typically performed on sitespecific scales, which can restrict the applicability of lessons learned to other sites. Thus, characterizing general trends in how restored sites compare to reference sites across locations, habitat types, and key taxonomic groups would be useful for restoration planners and practitioners in the northern GOM region charged with designing, implementing, and monitoring coastal restoration in the coming decades. To address this need, we conducted a systematic literature review and metaanalysis to evaluate regional trends in nekton utilization of restored and reference marshes in the northern GOM. We focused our meta-analyses on comparing nekton densities measured at restored and reference sites because most available studies provided information on these metrics. Our goal was to provide natural resource managers with information useful in planning, implementing, and evaluating coastal estuarine habitat management and restoration projects in the northern GOM.

\section{Materials and Methods}

\section{Nekton Density Compilation}

To evaluate the recovery rates of nekton density in restored marsh areas, we compiled nekton density data from restored and reference sites in the northern GOM from the scientific and gray literature. We defined reference marsh sites as minimally impaired, unrestored natural marsh, representative of the expected ecological conditions and integrity of other marsh sites in the region. Our approach is detailed in 
Hollweg et al. (2019) and summarized here. To identify papers with relevant information, we conducted a literature search consisting of a keyword search, an author-based search, and supplemental searches. First, we identified papers by conducting a keyword search in 12 databases available through the service ProQuest (http://www.proquest.com/) using a standardized set of relevant search terms (see Hollweg et al. 2019). We then conducted an author-based literature search where we included the authors identified in the keyword search with four or more publications; we also included three additional authors who appeared three times in the keyword search and who wrote papers we previously found relevant. We conducted the author search in the same 12 databases used for the keyword search with no additional limiters. Lastly, we identified additional papers using online search engines (e.g., Google Scholar, Louisiana State University Electronic Thesis and Dissertation Library), accessing individual digital libraries, and reviewing previously collected papers.

We reviewed the papers identified during the literature searches for relevant data on nekton density of coastal habitats in the northern GOM. Data tables were extracted from the published literature using Able2Extract Professional 8 software (http://www.investintech.com/), and data presented in the figures were manually extracted using DataThief III software (Tummers 2006). We checked all extracted data against the original tables or figures to ensure there were no transcription errors during the extraction process. When papers contained duplicate data from the same study, we only kept the most recent document. We compiled all data as reported in the original publication and retained statistical information such as the mean, standard error (SE), standard deviation (SD), and sample number $(\mathrm{N})$. In some cases, we standardized the data, including (1) conversion of density values to number of individuals $\mathrm{m}^{-2}$, (2) calculation of density (number of individuals $\mathrm{m}^{-2}$ ) if the paper reported abundance and sampling area, and (3) calculation of a total value for a group of species if the publication author(s) had not calculated this value and provided information that allowed this calculation. For example, if the paper provided total crustacean density $\left(\bar{y}_{C}\right)$ and total fish density $\left(\bar{y}_{F}\right)$, the total nekton density $\left(\bar{y}_{\text {TOTAL }}\right)$ was summed:

$\bar{y}_{\text {TOTAL }}=\bar{y}_{C}+\bar{y}_{F}$.

If the SE for the groups of organisms that were being summed was provided, we also calculated the SE of this total value using the following equation:

$S E(\widehat{\text { Total }})=\sqrt{S E_{C}^{2}+S E_{F}^{2}+2 r\left(S E_{C}\right)\left(S E_{F}\right)}$,

where $r$ is the sample correlation coefficient between the density of the crustacean taxa and the density of the fish taxa.
Using those records that provided both total crustacean density and total fish density, we calculated the Spearman's rank correlation between the densities of the two and found that the correlation was negligible $(r=0.06, N=246)$. Thus, the covariance term was dropped and the SE of the total nekton density was calculated as

$S E(\widehat{\text { Total }})=\sqrt{S E_{C}^{2}+S E_{F}^{2}}$.

In addition to the quantitative data, we compiled additional qualitative data including location information (i.e., state, longitude, latitude), restoration information if applicable (e.g., restoration type, year restored, age), habitat information (e.g., habitat type, salinity zone), sampling information (i.e., sampling year, sampling season, sampling month), and sampler information (i.e., sampler type, mesh size). We classified the habitat as marsh if the sampling site was located on the vegetated platform of the marsh surface. If the sampling site was located in open water away from the marsh shoreline, we classified the habitat as either non-vegetated bottom (NVB) or submerged aquatic vegetation (SAV) depending on site conditions. We assigned a salinity zone (i.e., saline, brackish, intermediate, or fresh) based on the vegetation community at the site, following the classification scheme outlined in Visser et al. (1998, 2000, 2002), Sasser et al. (2014), and Enwright et al. (2014). We used the vegetation community as a proxy for salinity zone because it represents average environmental conditions over time rather than a single salinity measurement at a location, which may vary greatly over different temporal scales (Rozas and Minello 2010; Mace and Rozas 2017). We recorded the season based on timing of the sampling, with spring defined as March, April, and May; summer as June, July, and August; fall as September, October, and November; and winter as December, January, and February. Standardized taxonomic information was validated using the Integrated Taxonomic Information System reference database (www. ITIS.gov). Finally, we conducted a $100 \%$ independent quality control check of the compiled data to ensure no errors were introduced during the data extraction and compilation process.

\section{Nekton Recovery Analysis}

To evaluate recovery patterns of nekton density at restored sites, we compared field-collected density data from restored and reference sites across the northern coast of the GOM. We focused our meta-analysis on marsh restoration projects, including (1) large-scale marsh creation that consisted of establishing marsh in open-water or fragmented habitat, and (2) the construction of marsh terraces using onsite subtidal sediment or offsite dredged material. We conducted two sets of analyses: "paired" analyses and "unpaired" analyses. In the paired 
analyses, we compared nekton densities at restored sites to densities at paired reference sites. Each restored and reference data pair was from the same study and collected during the same time period in a similar study area using the same gear. The objective of the paired analyses was to evaluate average within-study relationships between the restored and reference sites across all site pairings. The paired analyses take advantage of the selection of comparable reference locations, but are sensitive to the choice of that specific reference location. In the unpaired analyses, we compared average densities of nekton at all restored sites to densities measured at all reference sites, but restored and reference data were not necessarily from the same studies or sites. In contrast to the paired analyses, the unpaired analyses enable the evaluation of average nekton densities at restored sites relative to more generalized reference conditions in the northern GOM. We describe the methods for both sets of analyses in more detail below.

\section{Paired Analyses}

The objective of the paired analyses was to compare nekton densities measured at restored sites to paired reference densities as a function of the age of restored sites (defined as the time since the project was completed). First, we calculated a response ratio $(\mathrm{RR})$ for each record $(i)$, where

$R R_{i}=\ln \left(\frac{\text { Restored Mean Density }+0.01}{\text { Reference Mean Density }+0.01}\right)_{i}$

We only used restored and reference data pairs that were from the same study, collected during the same time period in a similar study area, and sampled using the same gear. In addition, we only paired a reference site to a restored site if it was clear that it was the intent of the study. A response ratio less than zero indicates that the restored site density is less than the reference site density; in contrast, a response ratio greater than zero indicates the restored site density is greater than the reference site density. This response ratio is similar to one used in a meta-analysis by Moreno-Mateos et al. (2012), but we added " 0.01 " instead of " 1 " to both restored and reference densities. We chose the smaller value since reported densities can be quite small, and because the addition of a large value relative to the range of reported values attenuates the response ratio estimates. By adding a constant, we were able to include nekton densities equal to zero at either a restored site or reference site in our analyses. However, we did not include data where both the reference density and restored density were equal to zero. This only occurred in the analyses of individual species grouped by family (see more detail below; the number of paired data points that were excluded from the analyses included 2 out of 18 for Palaemonidae and 1 out of 24 for Penaeidae). Results were reported as both modelestimated mean response ratios and their back-transformed values. The back-transformed values $\times 100 \%$ are interpreted as the mean percentages of density in restored marshes compared to that of reference marshes. So, for example, an estimated $\mathrm{RR}=-0.5$ represents a restored marsh density that is $61 \%$ of the value of the density reported in a reference marsh, expressed as a percent.

For the purpose of constructing confidence intervals (CIs) of the means for paired data, we calculated the variance of the response ratio as follows:

$\operatorname{Var}_{R R}=\left(\frac{S E_{\text {Restored }}}{\text { Restored Mean }+0.01}\right)^{2}+\left(\frac{S E_{\text {Reference }}}{\text { Reference Mean }+0.01}\right)^{2}$.

The inverse of the variance was used in constructing weighting factors in the meta-analyses [i.e., values with a high variance receive less weight in the meta-analysis and values that are considered to be more precise (with a low variance) receive greater weight]. Because this approach used the ratio of data collected using the same gear, within the same time period, and under similar environmental conditions (i.e., habitat type and salinity zone), we assumed that the relationship between the restored density and the paired reference density was independent of these factors; therefore, we did not perform separate analyses to account for them. However, we recognize that gear efficiency may differ at a natural marsh site compared to a restored marsh site, especially in the first few years after restoration when the restored site is still developing and vegetation is becoming established. For example, while enclosure gear types (e.g., throw traps) have been shown to be effective at sampling the marsh platform, their efficiency may decrease in thicker vegetation (Rozas and Minello 1997). While this correction conceptually could be incorporated into the analysis, we are not aware of any studies that have quantitatively investigated this difference and acknowledge it is an additional source of uncertainty in our analysis.

To investigate how nekton densities measured at restored sites at a given age compare to densities at reference sites, we calculated mean response ratios for total nekton density, total fish density, and total crustacean density (1) during the first 5 years following restoration (defined as the "early" time period) and (2) during a later time period where the age of the restored site was greater than 5 years (defined as the "late" time period). We used this 5-year threshold because existing literature suggests that aboveground biomass at restored marsh sites generally recovers within 2 to 5 years following restoration (Craft et al. 2002, 2003; Strange et al. 2002; Ebbets et al. 2019). We separated comparative analyses between studies that sampled nekton from the marsh platform and studies that sampled nekton in the open-water away from the marsh edge, including both NVB and areas with SAV. Since studies were paired, we included all seasons and salinity zones that were sampled. We describe $95 \%$ CIs for our data summaries 
and resulting contrasts. Given the nature of our meta-analysis and the underlying data, this approach provides for a transparent presentation of the variability in the data and comparisons between restored and reference locations.

We also evaluated response ratios relative to the age of the restored site. We performed this analysis for total nekton density, total fish density, and total crustacean density, as well as for densities of individual fish and crustacean species grouped by family (i.e., Gobiidae, Palaemonidae, Penaeidae, and Portunidae). These families were chosen based on their ecological role and/or economic importance and data availability. We performed this analysis for only studies that sampled nekton on the marsh platform. Since studies were paired, we included all seasons and salinity zones that were sampled. We fitted a weighted linear mixed model with the random effects of a study (i.e., literature reference) and record (i.e., observation) within a study, a fixed effect of categorical age (since restoration began), and weights equal to the inverses of the sums of the variances of response ratio and random effects. Denominator degrees of freedom were adjusted using the Kenward-Roger method (Kenward and Roger 1997). The random effects were tested using likelihood ratio tests $\left(\chi^{2}\right.$ with 1 degree of freedom). We calculated $95 \%$ CIs for the mean at each age. No adjustments were used for controlling the family-wise error rates as formal pairwise testing of differences among means was not performed. The assumption of normality was reviewed using the conditional residuals from the fitted model.

\section{Unpaired Analyses}

The objective of the unpaired analyses was to evaluate average nekton densities at restored sites relative to more generalized reference conditions in the northern GOM. Unlike the paired analyses where restored and reference site data pairs were collected in the same season, using the same gear, and under similar environmental conditions, for the unpaired analyses, we standardized studies by gear type and restricted comparisons to data collected from the same habitat type, salinity zone, and season. We developed a weighting factor for the meta-analysis by first imputing SEs for any observation with a missing variance value based on the relationship between the mean and SD of a record (i.e., observation), as described in Hollweg et al. (2019). Once all records had SEs associated with the reported densities, we corrected the densities for gear efficiency as described in more detail in Hollweg et al. (2019). Briefly, since gear types vary in their ability to capture target organisms and their capture ability may differ across different habitats (Rozas and Minello 1997), we determined habitatspecific gear correction factors for the different gear types included in the analysis (see Hollweg et al. 2019). We then applied the gear-efficiency value to reported densities using
$D_{s}^{G}=\frac{D_{s g}}{G_{g}}$

where $D_{s}^{G}$ is the corrected density for record $s, D_{s g}$ is the reported density for record $s$ and gear type $g$, and $G_{g}$ is the estimated efficiency for gear type $g$. The SE of the corrected density is obtained by first calculating the estimated variance of the inverse of the efficiency using the Delta method (Casella and Berger 2002), and then applying Goodman's (1960) equation for estimating the variance of the product of two independent random variables (see Hollweg et al. 2019). While we developed the gear corrections based on the best available information, we acknowledge that gear efficiencies may vary by habitat condition (e.g., vegetation structure), habitat maturation post-restoration, environmental conditions (e.g., turbidity, water depth), and sampling team. In addition to gear efficiency, the selectivity of the gear may also affect the measured densities of certain species. For example, some gear may have limitations in their ability to capture fish at specific lengths. Because we did not have information on gear selectivity for all of the species and life stages reported here, we did not attempt to correct for this factor and acknowledge this as a potential source of uncertainty in our analysis.

Similar to the paired analyses, we calculated average densities for total nekton, total fish, and total crustaceans during the "early" period (age of the restored site less than or equal to 5 years) and "late" period (age of restoration site greater than 5 years) and compared those densities to average densities across all reference sites. We also calculated the difference of the restored site mean density from the reference site mean density. We calculated 95\% CIs for each mean and the difference from the reference site. We restricted these unpaired analyses to studies that sampled nekton on the marsh platform in the saline zone, with comparative analyses separated between the spring and fall.

We also compared mean densities for total nekton, total fish, total crustaceans, and brown shrimp (Farfantepenaeus aztecus) at each age level of restored sites to the mean density for that taxonomic group at the reference sites. This analysis let us determine whether and when recovery had occurred for each taxonomic group. We restricted these unpaired analyses to studies that sampled nekton on the marsh platform in the saline zone, with comparative analyses separated between the spring and fall (F. aztecus analysis was only conducted for spring). We selected brown shrimp (F. aztecus) based on its economic importance and data availability. To conduct this analysis, we fitted a weighted linear mixed model to the data, treating age since restoration (binned into categories by year) as a fixed effect, and study (i.e., literature reference) and record (i.e., observation) within a study as random effects. We weighted the model based on the inverses of the variances of gear-corrected densities as weighting factors. All restored sites were reported with their age (i.e., time since restoration). For 
the purposes of the statistical analysis, all reference sites were assigned an age of 99, which allowed for comparisons of densities of restored sites to reference values for each age of restored sites for which there were data. An age of 99 was chosen only for convenience in the modeling, and not for any inference about the age of reference locations. Denominator degrees of freedom were adjusted using the Kenward-Roger method (Kenward and Roger 1997). The random effects were tested using likelihood ratio tests $\left(\chi^{2}\right.$ with 1 degree of freedom). The assumption of normality was reviewed using the conditional residuals from the fitted model. We calculated 95\% CIs for the differences between means at each age and the mean at age 99 .

\section{Results}

\section{Nekton Density Compilation}

We identified a total of 841 publications from our literature search, of which 121 publications passed the initial screening criteria (Hollweg et al. 2019). When papers contained duplicate data from the same study, we maintained the most recent document and discarded the other(s). Overall, we compiled nekton data from 106 publications, spanning from Florida to Texas (Hollweg et al. 2019).

We limited the meta-analysis to the habitat-season combinations discussed above. Of the 106 papers we compiled, we included data from 29 publications in the meta-analyses (Tables S1 and S2 in Supplemental Information). The majority of studies included in the meta-analyses were located in Louisiana and Texas (Fig. 1).

\section{Paired Analyses}

The paired analyses included 13 studies that were located within Louisiana or Texas and included saline to intermediate salinity zones (Fig. 1, Table S1 in Supplemental Information). Restored sites included both large-scale marsh creation and construction of marsh terraces and varied in age from 1 year to more than 30 years. For large-scale marsh creation, the substrate was typically offsite dredged material, but some studies used upland sediment or natural shoreline. For marsh terraces, the substrate was most commonly onsite subtidal sediment, but some sites used offsite dredged material, a combination of both onsite and offsite sources, or did not specify. All terrace marsh sites were planted with vegetation following construction; some of the large-scale marsh creation sites were actively vegetated while other sites allowed natural recolonization.

Of the 13 studies included in the paired analyses, 5 studies sampled nekton on the marsh platform (Table 1), which included sites that were sampled near the marsh edge (within
$5 \mathrm{~m}$ ) and sites that were sampled farther inland. Of the marsh dataset, three studies were from large-scale marsh creation projects and two studies were from marsh terrace projects. Eleven studies sampled nekton within open-water habitat of restored and reference marshes, which included both NVB and areas with SAV (Table 1). Of the open-water dataset, two studies were from large-scale marsh creation projects, eight studies were from marsh terrace projects, and one study sampled both types of restoration projects. Open-water sampling locations included sites within $5 \mathrm{~m}$ of the marsh shoreline and sites that were farther from shore. Three studies sampled both marsh and open-water habitat. A number of studies conducted sampling at different locations and/or during different seasons, which resulted in 87 unique paired sampling events.

For marsh habitat samples, mean densities of total nekton at restored sites were smaller than at paired reference sites, both during the "early" period following restoration and the "late" period (Table 2, Fig. 2a). During the early period, the mean response ratio was -0.699 , which equates to a mean relative density at restored sites of $49.7 \%$ (95\% CI: $26.6-$ $93.0 \%$ ) relative to that at the reference sites. Relative densities during the late period were higher, with a mean relative density at restored sites $73.1 \%$ of reference locations $(95 \%$ CI: $46.1-116.1 \%$ ). Whereas the upper $95 \%$ CI of the mean relative density of restored to reference sites did not include or exceed $100 \%$ during the early period (i.e., the upper $95 \% \mathrm{CI}$ of the mean response ratio was $<0$ ), the upper $95 \% \mathrm{CI}$ exceeded $100 \%$ during the late period (i.e., the upper $95 \% \mathrm{CI}$ of the mean response ratio overlapped 0 ). Results for total crustaceans in marsh habitats were similar to total nekton, with mean densities at restored sites $35.6 \%$ of reference locations (95\% CI: $16.6-76.7 \%$ ) during the early period and $71.3 \%$ of reference locations (95\% CI: 42.7-119.2\%) during the late period. The upper $95 \% \mathrm{CI}$ of the mean relative density of restored to reference sites did not include or exceed $100 \%$ during the early period, but did so during the late period. Mean relative densities of fish at marsh habitat sites were highly variable and somewhat lower at restored sites during both time periods. During the early period, mean fish density at restored sites was approximately $85 \%$ of reference locations (95\% CI: 33.5-215.3\%). During the late period, mean fish density at restored sites was approximately $77 \%$ of reference locations (95\% CI: 39.3-152.7\%). The 95\% CIs of the mean relative densities of restored to reference sites included $100 \%$ during both early and late periods.

At open-water habitats, all contrasts were highly variable and did not demonstrate consistent patterns (Table 2, Fig. 2b). Total nekton densities at restored sites were similar to paired reference sites during the early period following restoration $($ mean $=102 \%$; 95\% CI: $54.2-191.1 \%)$ and greater than reference sites during the late period (mean $=245 \%$; $95 \%$ CI: $115.2-520.5 \%$ ). Response ratios for total fish in open-water 
Fig. 1 Geographic distribution of sampling locations included in the paired analyses (top) and unpaired analyses (bottom). Paired analyses included studies that were conducted in marsh, SAV, or NVB during any season and across any salinity zone. Unpaired analyses included studies that were conducted in saline marsh on the marsh platform during the spring or fall. Since some studies conducted sampling at multiple locations, they may contain more than one marker. In addition, some studies may have combined data across sampling locations

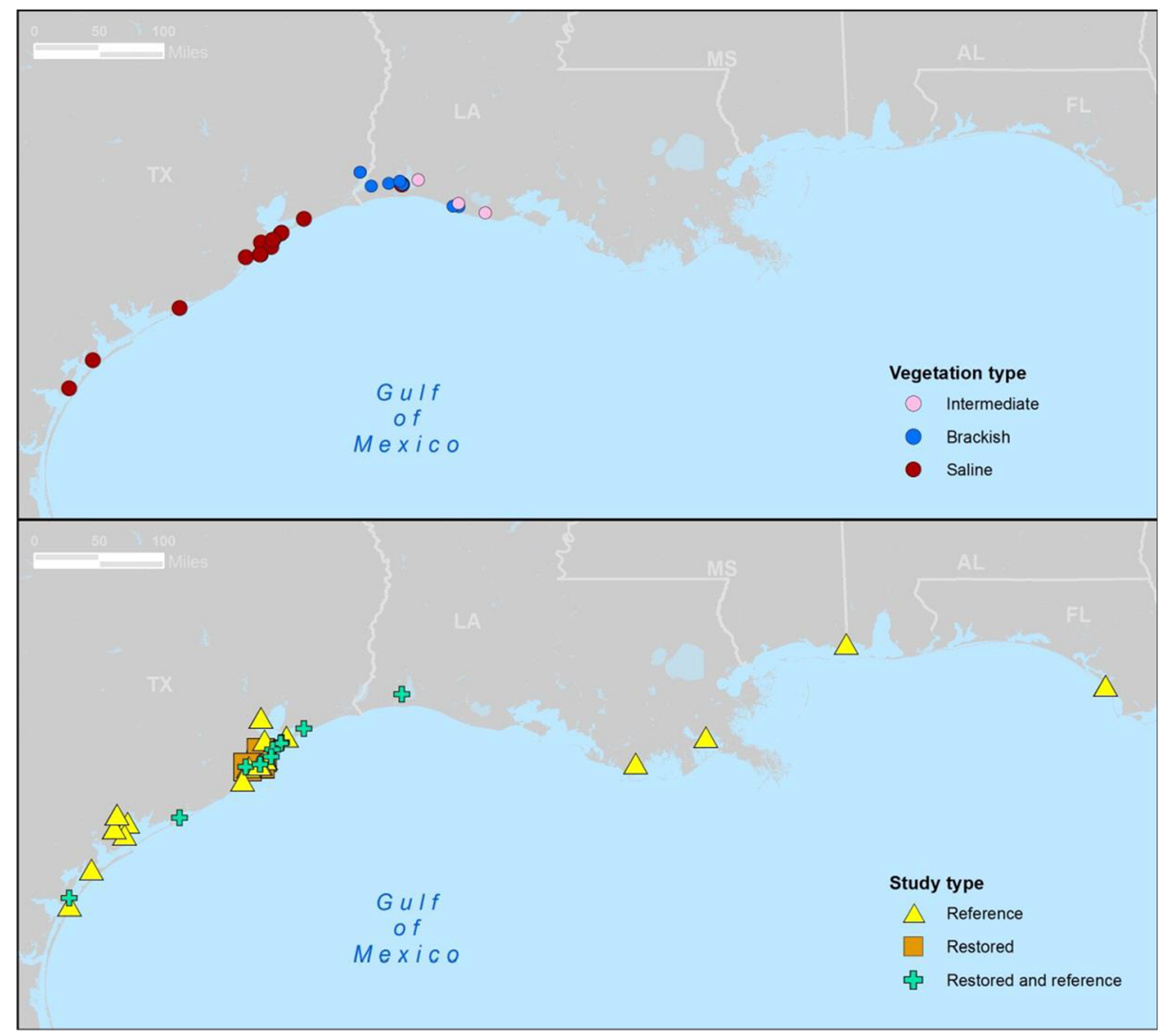

habitat were similar to results from the marsh platform, with mean densities at restored sites $86.4 \%$ of reference locations (95\% CI: $19.8-376.5 \%$ ) during the early period and $72.4 \%$ of reference locations (95\% CI: $0.3-15,141 \%$ ) during the late period, with high variability across studies. Mean relative densities of crustaceans at open-water habitat sites were highly variable and showed a decreasing trend from the early $($ mean $=159 \%$; 95\% CI: $63.8-396.1 \%)$ to the late (mean $=$ 94\%; $95 \%$ CI: $27.1-327.0 \%$ ) periods. The $95 \%$ CIs of the mean relative densities of restored to reference sites were relatively large and overlapped $100 \%$, with the exception of total nekton during the late period, where the lower 95\% CI did not include and exceeded $100 \%$.

Table 1 Number of studies (and sampling events) by habitat type and salinity zone included in the paired analyses

\begin{tabular}{lll}
\hline Salinity zone & Marsh & $\begin{array}{l}\text { Open water (SAV } \\
\text { or non-vegetated) }\end{array}$ \\
\hline Saline & $5(28)$ & $4(22)$ \\
Brackish & $0(0)$ & $6(35)$ \\
Intermediate & $0(0)$ & $1(2)$ \\
Total & $5(28)$ & $11(59)$ \\
\hline
\end{tabular}

When we evaluated relationships between response ratio and the number of years following restoration, we observed an increasing trend over time for total nekton and total crustacean densities measured on the marsh platform for years 2 through 15 , with response ratios approaching zero by approximately year 13 (Fig. 3ac, Table S3 in Supplemental Information). However, the 95\% CIs of mean response ratios overlapped 0 for all time steps. We did not see a similar pattern for total fish, where response ratios remained similar and close to 0 throughout the initial 15 -year period, with the $95 \%$ CIs overlapping 0 for all time steps (Fig. 3b). For total nekton, total fish, and total crustaceans, response ratios were markedly lower in the year 30 sample, with this value driven by low nekton densities measured at a restored marsh site in Guadalupe Estuary, Texas (Zeug et al. 2007). At this site, the authors found that lower oyster substrate and soil organic content in the created marsh reduced measures of nekton similarity relative to the reference marsh (Zeug et al. 2007).

Examination of recovery trajectories at the family-level highlighted taxonomic variation in temporal trends (Fig. 4, Table S4 in Supplemental Information). Response ratios of gobies (Family Gobiidae) were less than zero for all time periods and appeared to show a decreasing trend over the initial 10 years (Fig. 4a). Grass shrimp (Family Palaemonidae) also showed a decreasing trend, with response 
Table 2 Overall percent difference (\% restored density vs. reference density) and response ratios $[\ln ($ restored mean density $+0.01 /$ reference mean density +0.01 )] for each group (total nekton, total fish, and total crustaceans) calculated from densities measured at restored sites for each post-restoration time period (early: age of restored sites 2 to 5 years; late: age of restored sites $>5$ years) and densities measured at paired reference sites for each habitat type (marsh and open-water). Grand mean (mean) and standard error (SE, only for response ratio) with lower and upper bounds (LB and UB, respectively) of $95 \%$ CIs were calculated from $N$ number of samples

\begin{tabular}{|c|c|c|c|c|c|c|c|c|c|}
\hline \multirow[t]{3}{*}{ Group } & \multirow[t]{3}{*}{ Time period } & \multicolumn{3}{|c|}{$\%$ restored vs. reference } & \multicolumn{4}{|c|}{ Response ratio } & \multirow[t]{3}{*}{$N$} \\
\hline & & \multirow[t]{2}{*}{ Mean } & \multicolumn{2}{|c|}{$95 \% \mathrm{CI}$} & \multirow[t]{2}{*}{ Mean } & \multirow[t]{2}{*}{ SE } & \multicolumn{2}{|l|}{$95 \% \mathrm{CI}$} & \\
\hline & & & LB & UB & & & LB & UB & \\
\hline \multicolumn{10}{|l|}{ Marsh habitat } \\
\hline \multirow[t]{2}{*}{ Nekton } & Early & 49.7 & 26.6 & 93.0 & -0.699 & 0.272 & -1.326 & -0.073 & 7 \\
\hline & Late & 73.1 & 46.1 & 116.1 & -0.313 & 0.201 & -0.775 & 0.149 & 11 \\
\hline \multirow[t]{2}{*}{ Fish } & Early & 85.0 & 33.5 & 215.3 & -0.163 & 0.409 & -1.093 & 0.767 & 7 \\
\hline & Late & 77.4 & 39.3 & 152.7 & -0.256 & 0.298 & -0.935 & 0.423 & 11 \\
\hline \multirow[t]{2}{*}{ Crustacean } & Early & 35.6 & 16.6 & 76.7 & -1.032 & 0.339 & -1.798 & -0.265 & 7 \\
\hline & Late & 71.3 & 42.7 & 119.2 & -0.338 & 0.225 & -0.851 & 0.175 & 11 \\
\hline \multicolumn{10}{|c|}{ Open-water habitat (NVB and SAV) } \\
\hline \multirow[t]{2}{*}{ Nekton } & Early & 101.8 & 54.2 & 191.1 & 0.017 & 0.273 & -0.613 & 0.648 & 12 \\
\hline & Late & 244.9 & 115.2 & 520.5 & 0.896 & 0.346 & 0.142 & 1.650 & 8 \\
\hline \multirow[t]{2}{*}{ Fish } & Early & 86.4 & 19.8 & 376.5 & -0.146 & 0.116 & -1.618 & 1.326 & 16 \\
\hline & Late & 72.4 & 0.3 & $15,141.1$ & -0.323 & 0.421 & -5.665 & 5.020 & 2 \\
\hline \multirow[t]{2}{*}{ Crustacean } & Early & 159.0 & 63.8 & 396.1 & 0.464 & 0.373 & -0.449 & 1.376 & 10 \\
\hline & Late & 94.1 & 27.1 & 327.0 & -0.061 & 0.494 & -1.306 & 1.185 & 2 \\
\hline
\end{tabular}

ratios less than zero after the initial 3 years (Fig. 4b). All response ratios for penaeid shrimp (Family Penaeidae) were less than zero, with no apparent temporal trend (Fig. 4c). Response ratios for portunid crabs [Family Portunidae, specifically blue crab (Callinectes sapidus)] were close to or greater than zero over time (Fig. 4d). For all taxa, the 95\% CIs of mean response ratios overlapped 0 for all time steps, with the exception of Palaemonidae at year 5, where the upper 95\% CI did not include or exceed 0 .

\section{Unpaired Analyses}

For the unpaired analyses, we included nekton density data from 21 studies conducted in restored and/or reference marsh sites spanning from Florida to Texas (Fig. 1, Table S2 in Supplemental Information). Similar to the paired analyses, sampling locations on the marsh platform included sites near the marsh edge (within $5 \mathrm{~m}$ ) as well as sites further inland. Of the 21 studies, 4 studies contained both restored and reference site data, 2 studies contained only restored site data, and 15 studies contained only reference site data. Restored sites included both large-scale marsh creation (3 studies) and marsh terraces ( 3 studies), and ranged in age from 2 to 15 years. For large-scale marsh creation, the substrate was typically offsite dredged material, but in some studies the substrate consisted of upland sediment, natural shoreline, or was not specified. For marsh terraces, the substrate was either onsite subtidal sediment or not specified. All terrace marsh sites were planted with vegetation following construction; some of the largescale marsh creation sites were actively vegetated while other sites allowed natural recolonization. A number of studies conducted sampling at different locations and/or during different seasons, which resulted in 41 unique sampling events for restored sites and 98 unique sampling events for reference sites.

In the spring sampling, total nekton density (Fig. 5a, Table S5 in Supplemental Information) and total crustacean density (Fig. 5c, Table S7 in Supplemental Information) were roughly half of the reference densities during the early period, with mean densities approaching reference conditions during the late period. For total fish, mean densities in the spring sampling exceeded average reference conditions during both the early and late periods (Fig. 5b, Table S6 in Supplemental Information). The $95 \%$ CIs of the difference between means overlapped 0 for all totals in spring, with the exception of total nekton during the early period. Fish made up a small percentage of the total nekton density in both the spring and fall.

Mean densities for total nekton, total fish, and total crustaceans during the fall sampling were less than reference densities during the early period, but showed an increase over reference conditions during the late period (Fig. 5, Tables S5-S7 in Supplemental Information). In all instances, the 95\% CIs of the difference between means overlapped 0 . The increase in mean densities in the late period was driven by extremely high densities in one study from a 15-year-old marsh in Galveston 

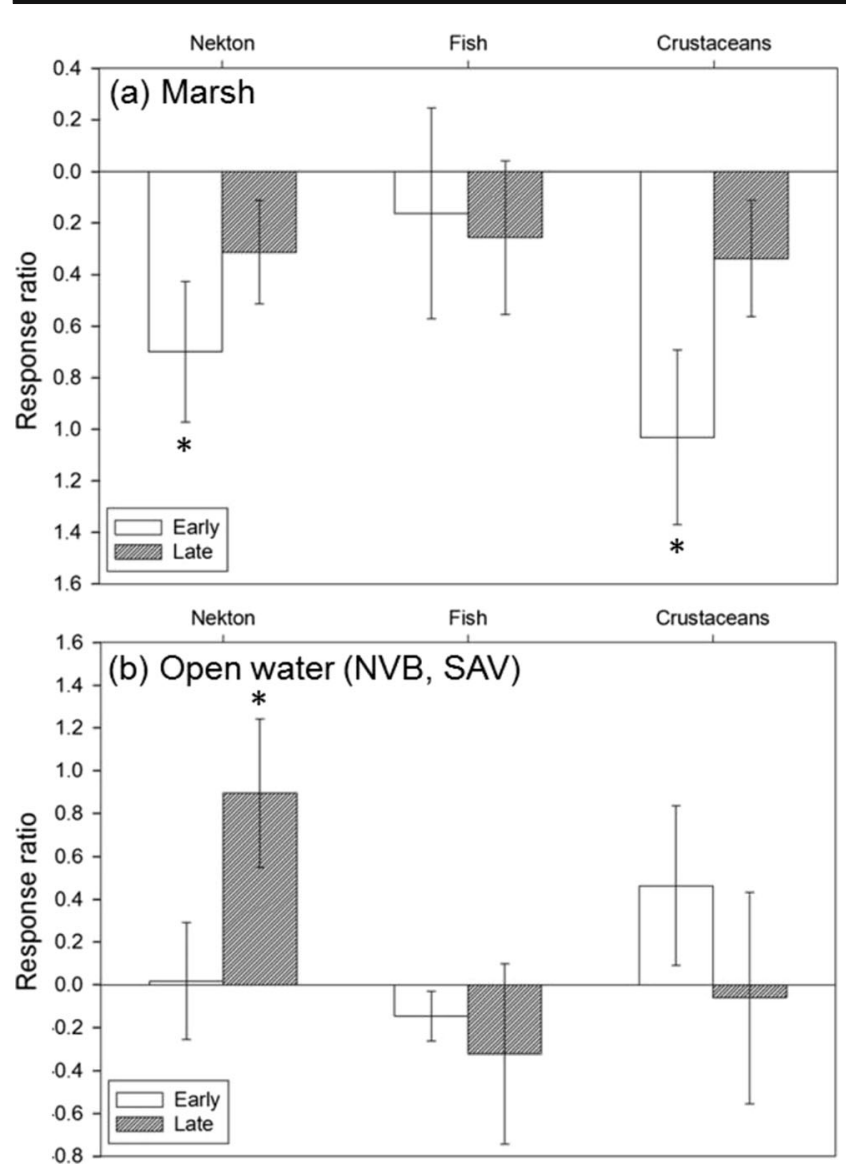

Fig. 2 Response ratios $[\ln$ (restored mean density $+0.01 /$ reference mean density +0.01 ) ] of total nekton, total fish, and total crustaceans across paired reference and restored sites in a marsh habitat and $\mathbf{b}$ open-water habitat (NVB and SAV) for early (age of restored sites $=2$ to 5 years; white bars) and late (age of restored sites $>5$ years; striped bars) time periods. Values shown are averages $( \pm \mathrm{SE})$. A response ratio of 0 implies equality of the mean densities between restored and reference sites. A value greater than zero indicates that the restored site density is greater than the reference site density. A response ratio less than zero indicates that the restored site density is less than the reference site density. An * indicates a mean response ratio where the $95 \%$ CI does not overlap 0

Bay, Texas, where Minello and Webb (1997) measured total nekton densities almost 3 times greater in the restored marsh compared to the reference marsh. During the spring, the same restored marsh had relatively similar mean densities of fish and crustaceans compared to the reference marsh. Unlike many of the other created marshes that we included in our analysis, which typically used offsite dredge material as the substrate, this site established marsh on natural shoreline. This difference in marsh restoration techniques may explain some of the variability that we observed between studies.

Inspection of the same data when the age of restored sites was considered demonstrated inconsistent trends (Fig. 6, Tables S5-S7 in Supplemental Information). From the spring dataset, nekton and crustacean mean densities at restored sites were lower than reference site values, particularly during the initial 5 years, but illustrated a
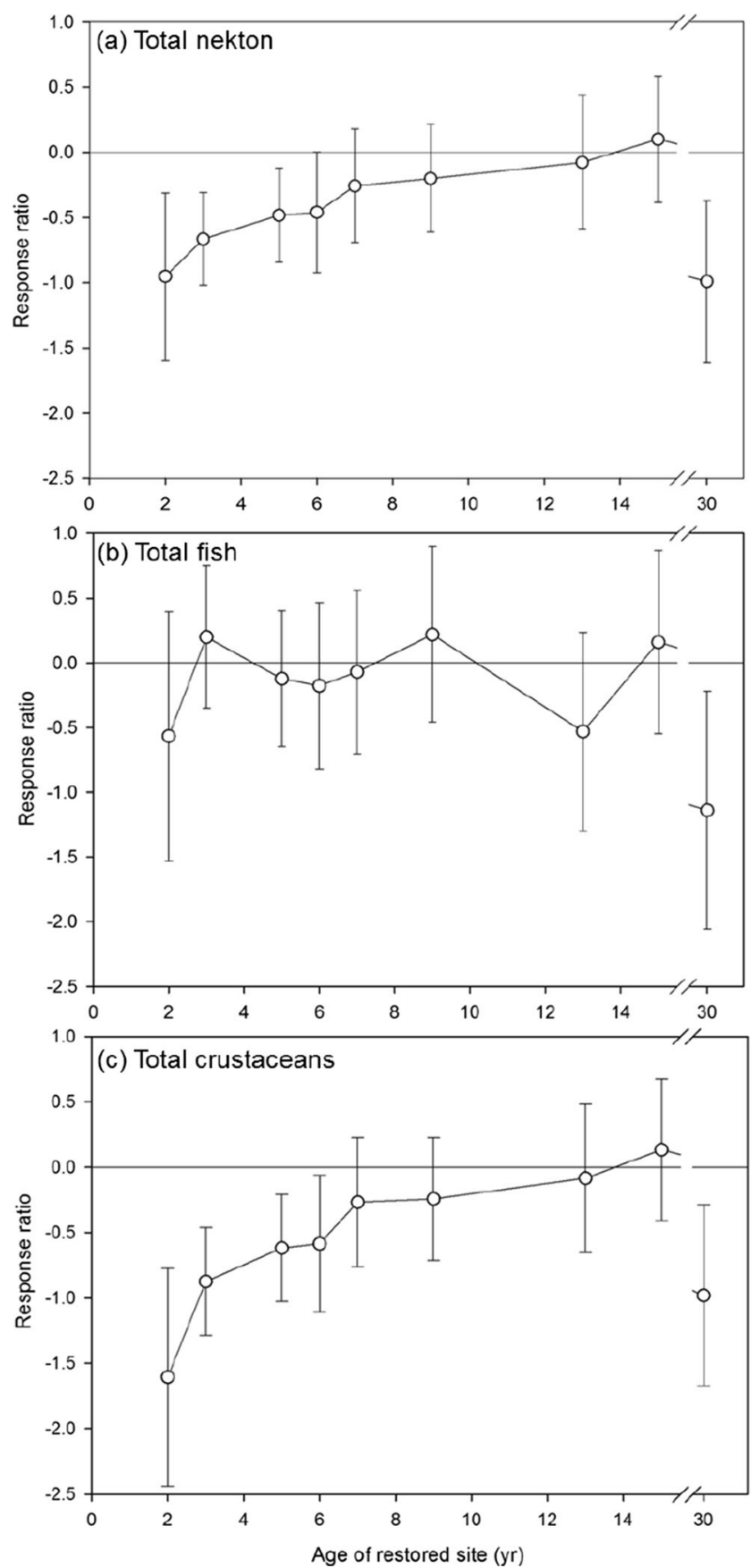

Fig. 3 Response ratios $[\ln ($ restored mean density $+0.01 /$ reference mean density +0.01 )] of a total nekton, $\mathbf{b}$ total fish, and $\mathbf{c}$ total crustaceans shown by age of restored site (i.e., years since restoration) across paired reference and restored sites in marsh habitat. Values shown are averages $( \pm \mathrm{SE}) ; 18$ total observations were used in each of the analyses. A response ratio greater than zero indicates that the restored site density is greater than the reference site density. A response ratio less than zero indicates that the restored site density is less than the reference site density. The $95 \%$ CIs of all mean response ratios overlapped 0

somewhat increasing trend over time (Fig. 6a and e, Tables S5 and S7 in Supplemental Information). For ages $2,3,5$, and 15 for total nekton and ages 2, 3, and 5 for total crustaceans, the upper $95 \%$ CIs of the difference between 

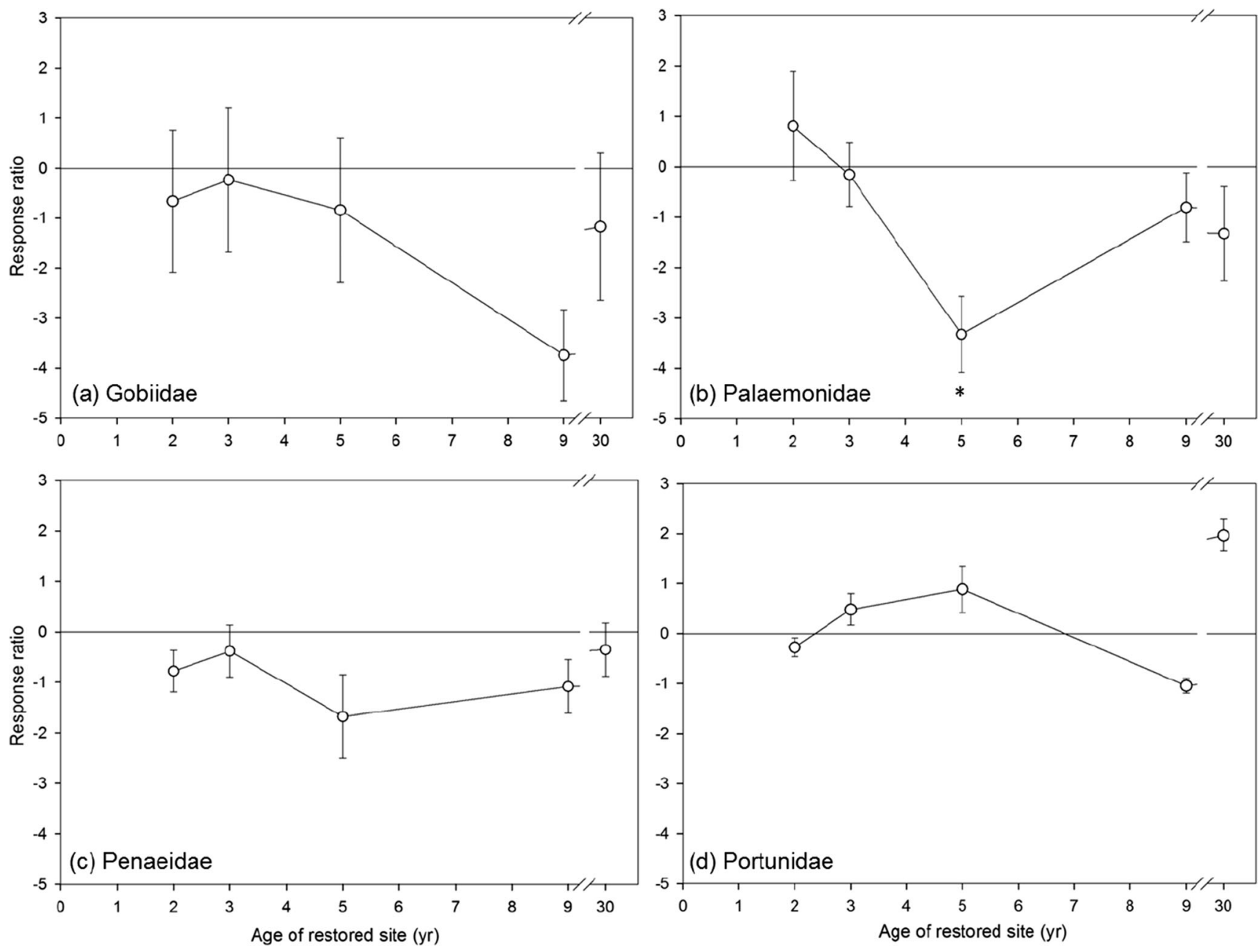

Fig. 4 Response ratios [ $\ln$ (restored mean density $+0.01 /$ reference mean density +0.01$)$ ] of a Family Gobiidae ( $n=13$ observations), b Family Palaemonidae ( $n=16$ observations), c Family Penaeidae $(n=23$ observations), and d Family Portunidae ( $n=10$ observations) shown by age of restored site (i.e., years since restoration) across paired reference and restored sites in marsh habitat. Values shown are averages $( \pm \mathrm{SE})$. A

means did not include or exceed 0. During fall, however, no similar trend was observed (Fig. $6 \mathrm{~b}$ and $\mathrm{f}$, Tables S5 and S7 in Supplemental Information). While restored mean density values were generally less than reference means, there was no clear trend over time. For both total nekton and total crustaceans, the upper $95 \%$ CIs of the difference between means included and exceeded 0 for every age except for year 6 . For fish densities, no increasing trends over time were observed in either the spring or fall sampling, with restored site mean densities both above and below reference values over time (Fig. $6 \mathrm{c}$ and d, Table S6 in Supplemental Information). At the species level, we only had sufficient data to evaluate densities of brown shrimp (F. aztecus) during the spring (Fig. 7, Table $\mathrm{S} 7$ in Supplemental Information). Brown shrimp mean densities at restored sites were lower than that for reference sites for all time periods and appeared to remain relatively constant response ratio greater than zero indicates that the restored site density is greater than the reference site density. A response ratio less than zero indicates that the restored site density is less than the reference site density. An $*$ indicates a mean response ratio where the $95 \%$ CI does not overlap 0

between years 3 and 9. For ages 2 and 9, the upper 95\% CIs of the difference between means did not include or exceed 0 .

\section{Discussion}

\section{Nekton Recovery}

Results of our meta-analyses across sites, species, and studies illustrated that total nekton mean densities - and constituent crustacean mean densities - at restored sites were generally lower than mean densities measured at reference sites. For marsh habitats, our results for both paired and unpaired comparisons showed that mean total nekton and crustacean densities at restored sites generally were lower than those for reference sites during the first decade following restoration. In the 



Fig. 5 Estimated mean densities (individuals $\mathrm{m}^{-2} \pm \mathrm{SE}$ ) of a total nekton, b total fish, and $\mathbf{c}$ total crustaceans in restored and reference sites in saline marsh during the spring and fall. Restored site values for bar graphs are averages over early (age of restored sites $=2$ to 5 years) and late (age of restored sites $>5$ years) time periods. An * indicates where the $95 \% \mathrm{CI}$ of the difference between means does not overlap 0

paired analyses, the partial recovery of total nekton and total crustacean mean densities toward reference densities was observed during the late time period (greater than 5 years following restoration) relative to the early time period (less than or equal to 5 years following restoration), although mean nekton densities at restored sites remained lower than at reference locations. Because crustaceans accounted for the majority of total nekton abundance, overall trends in nekton mean densities generally mirrored those of crustacean mean densities. When we evaluated nekton mean densities in the unpaired analyses, we observed a similar pattern of general increases in total nekton and crustacean mean densities toward reference ranges in the spring sampling. However, no such patterns were observed in the fall sampling. Possible explanations for this inconsistency could be due to differences in nekton utilization of marsh habitat between the spring and fall months, or the variety of locations and sampling times available for the unpaired analyses. Nekton community composition varies seasonally in estuarine marshes due to recruitment and migration of specific taxa (e.g., Rozas et al. 2007), which would result in response ratios being driven by the specific species that are present during that time period and their respective responses to the restored habitat. In addition, smallscale patterns of species utilization have been observed to vary seasonally across the marsh landscape, with peaks in abundances of some species shifting between the marsh interior and marsh edge, or from the marsh platform to NVB over different months (e.g., Minello and Rozas 2002; Rozas and Minello 2015).

For fish, restored site mean densities within marsh habitats were variable but relatively comparable to reference sites regardless of age. In the paired analysis, mean response ratios were somewhat negative, highly variable, and similar to one another in the early and late time periods. When we examined response ratios relative to the number of years following restoration, restored site mean densities were generally similar to reference sites and response ratios remained essentially unchanged from years 2 to 15 . Similarly, we did not see an increasing trend in fish densities at restored sites in the unpaired analyses, with restored site density values both above and below reference values over time.

Results among fish and crustacean species and families supported patterns observed at the broader taxonomic groupings described above. For example, densities of many crustacean taxa [e.g., penaeid shrimp (Family Penaeidae), grass shrimp (Family Palaemonidae)] and some fish taxa [e.g., gobies (Family Gobiidae)] were generally lower at restored sites than at reference sites.

Our results reflect previous findings from individual sites and studies in the northern GOM, many of which were also included in our meta-analysis. Several studies, all of which were sampled on the marsh platform, reported lower fish and/or crustacean densities in restored marshes compared to reference sites (e.g., Minello and Zimmerman 1992; Minello and Webb 1997; Rozas and Minello 2001; Zeug et al. 2007); however, these findings were not necessarily consistent across species or seasons. For example, significantly lower total crustacean densities were measured in restored marshes compared to reference marshes, mainly driven by differences in abundance of daggerblade grass shrimp (Palaemonetes pugio) and 

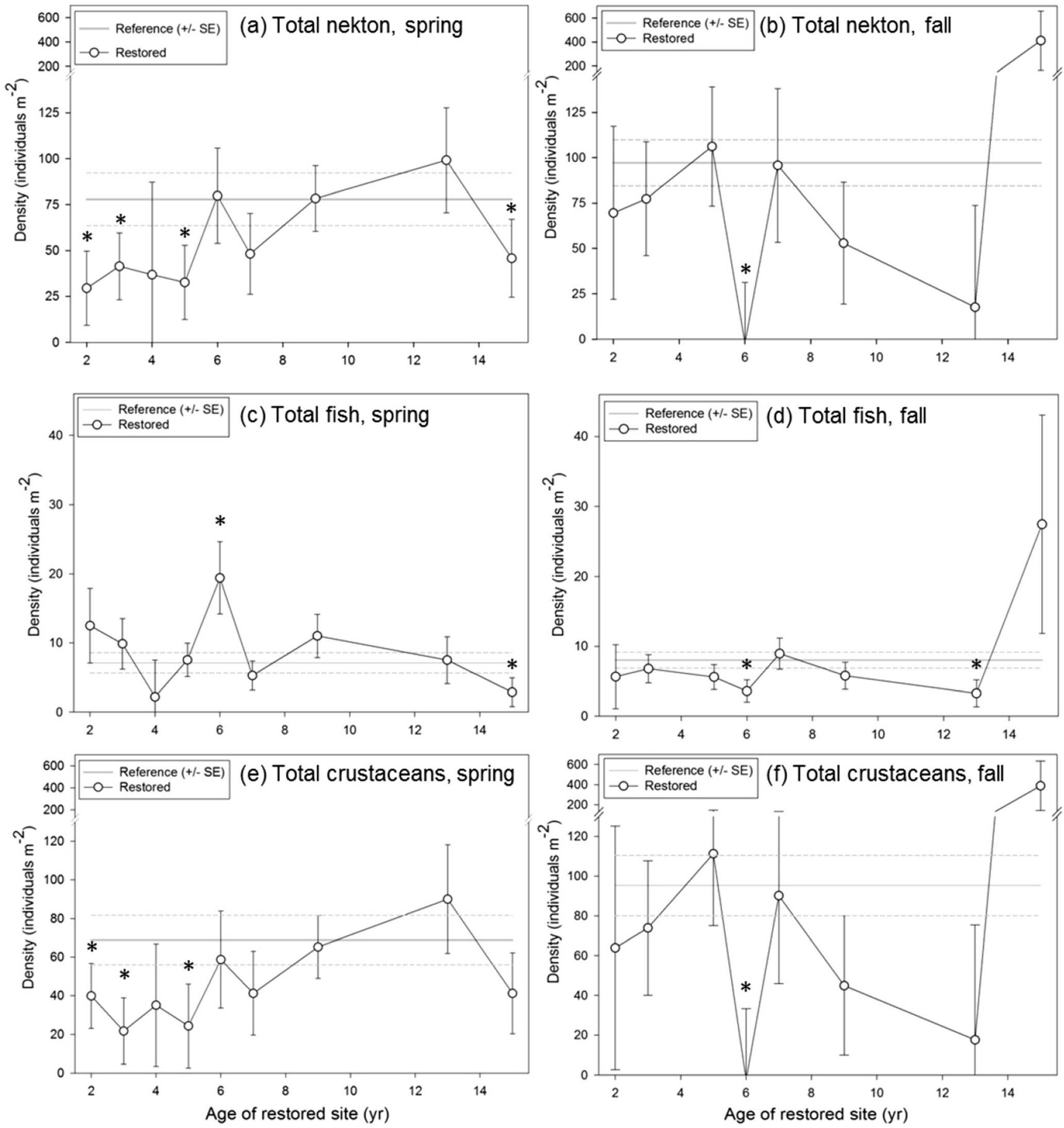

Fig. 6 Estimated spring (left column) and fall (right column) mean densities (individuals $\mathrm{m}^{-2} \pm \mathrm{SE}$ ) of $\mathbf{a}, \mathbf{b}$ total nekton, $\mathbf{c}, \mathbf{d}$ total fish, and e, $\mathbf{f}$ total crustaceans in saline marsh from the weighted linear mixed

brown shrimp (F. aztecus) (Minello and Zimmerman 1992). However, densities of fish [dominated by the darter goby (Ctenogobius boleosoma) and pinfish (Lagodon rhomboides)] were not significantly different between reference and restored marshes (Minello and Zimmerman 1992). In another study, total fish densities were lower in restored marshes compared to reference marshes during model by age of restored site compared with reference values (mean: solid line; SE: dotted lines). An * indicates where the $95 \%$ CI of the difference between means does not overlap 0

the spring and fall, while total crustacean densities were lower in restored marshes during the spring; and statistically significant differences were observed for densities of gobies (Family Gobiidae), pinfish (L. rhomboids), marsh grass shrimp (Palaemonetes vulgaris), brown shrimp (F. aztecus), white shrimp (Litopenaeus setiferus), and blue crab (C. sapidus) (Minello and Webb 1997). 
Fig. 7 Estimated spring mean density (individuals $\mathrm{m}^{-2} \pm \mathrm{SE}$ ) of brown shrimp (F. aztecus) in saline marsh from the weighted linear mixed model by age of restored site compared with reference values (mean: solid line, SE: dotted lines). An $*$ indicates where the $95 \%$ CI of the difference between means does not overlap 0

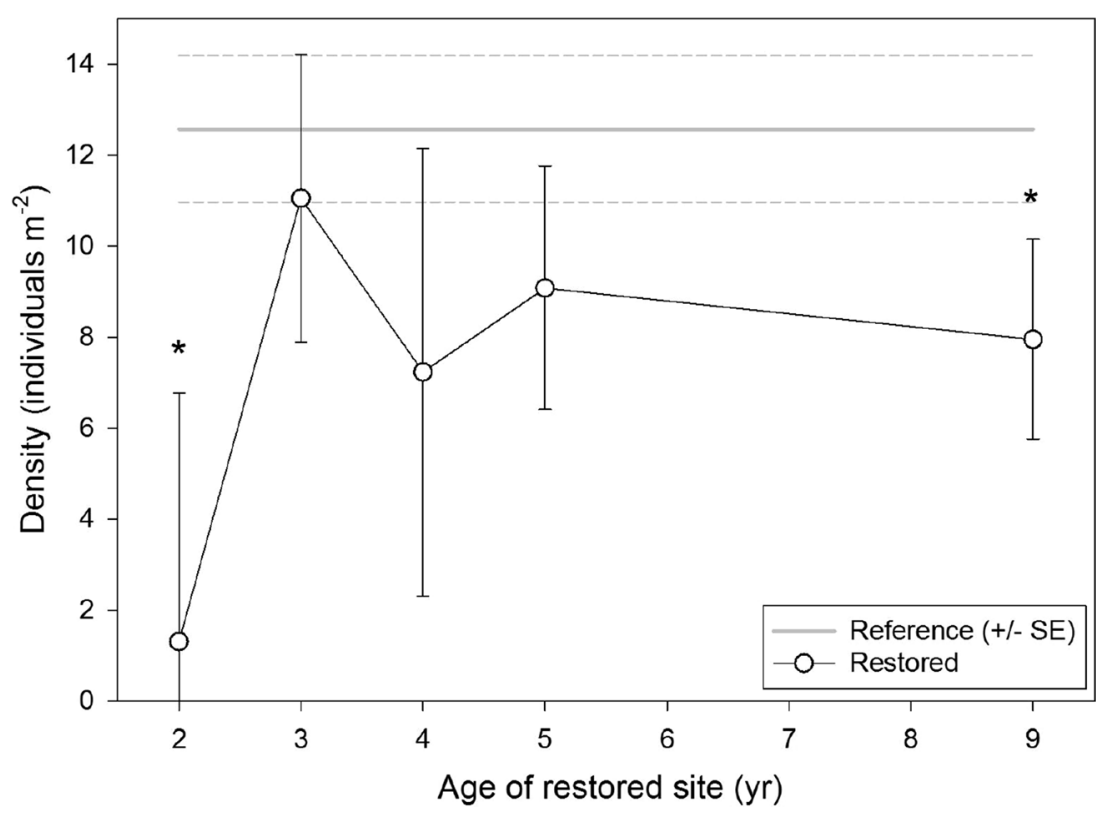

Other studies in the northern GOM, however, found comparable densities of nekton in restored and reference marsh sites (e.g., Thom et al. 2004; La Peyre et al. 2007; Rozas and Minello 2007; Llewellyn and La Peyre 2011; La Peyre and Gordon 2012). Notably, all of these studies were conducted in open-water habitat adjacent to the marsh edge, with the exception of Rozas and Minello (2007). In our meta-analysis, we were unable to find any clear trend in nekton utilization of restored and reference sites when sampling was conducted in open-water habitat. Since species preference for marsh versus shallow open-water habitat differs by taxa (e.g., Rozas et al. 2007; Rozas and Minello 2015; Hollweg et al. 2019), it is possible that species assemblage of open-water sites is less affected by the recovery of the restored marsh habitat. For example, many species that are found in open-water habitat [e.g., bay anchovy (Anchoa mitchilli), Gulf menhaden (Brevoortia patronus)] are pelagic and can be categorized as generalists that are not strongly affected by habitat condition or quality.

While our results showed that total nekton and crustacean mean densities were generally lower in the first few years at restored sites, other site-specific studies conducted at restored marshes in the northern GOM found no clear trend in nekton densities over time (e.g., Minello and Webb 1997; Minello 2000). For example, although Minello and Webb (1997) found significantly lower densities for many commercially important crustacean species in created marshes of different ages ( 3 to 15 years) compared to natural marshes, they did not observe a relationship between nekton densities and marsh age. Minello (2000) measured lower nekton densities at a 4month-old created marsh compared to two older created marshes ( 5 and 9 years), but this younger marsh reached similar densities to its older counterparts within 1 year. The author, however, concluded that all three created marshes were functioning at lower levels than natural marshes (Minello 2000).

Reasons for the lack of recovery of nekton in restored marsh that we observed in our meta-analysis may be attributed to higher elevations and lower flooding duration (Minello and Webb 1997), and the slow development of sediment characteristics and related prey availability (Minello and Zimmerman 1992; Thom et al. 2004; Zeug et al. 2007). The physical structure of restored habitats relative to abiotic influences can be an important determinant of nekton utilization. The marsh hydroperiod is known to affect nekton use of salt marsh habitat (Rozas 1995), and differences between restored and reference sites have also been attributed to elevation and flooding (Minello and Webb 1997). For example, in a study in Galveston Bay, Texas, Minello and Webb (1997) noted that the tidal flooding of five natural marshes was similar, with consistently lower marsh elevations and high flooding durations. However, tidal flooding was highly variable among created marshes (Minello and Webb 1997). Although not focused on created marshes, a number of field and modeling studies point to marsh elevation and flooding patterns as important indicators of their value for and use by nekton (e.g., Rozas and Reed 1993; Kneib and Wagner 1994; Rozas and Zimmerman 2000; Roth et al. 2008; Minello et al. 2012; Baker et al. 2013; Rozas and Minello 2015). Another important physical feature of restored marshes is the amount of marsh edge at a site. For example, marsh terraces are hypothesized to support high fisheries populations (Rozas et al. 2005; Rozas and Minello 2007) because they have a high marsh edge to area ratio, and nekton densities have been observed to be highest at this transition between marsh and open water (Baltz et al. 1993; Peterson and Turner 1994; Minello and Rozas 2002; Minello et al. 
2008; Rozas and Minello 2015). Thus, the physical structure of a restored site must be carefully designed to ensure maximized recovery of ecological function, including that represented by nekton density.

Although structural attributes of a created marsh such as vegetative structure (e.g., above-ground biomass and percent cover) may recover in the first few years, other ecological functions recover more slowly (Craft et al. 2002, 2003; Strange et al. 2002; Ebbets et al. 2019). Because emergent marsh vegetation is likely the principal source of organic matter to soils (Craft et al. 1988a, 1988b; Broome et al. 2000) and many marsh creation projects often use dredged material that is low in organic matter content (Broome et al. 2000; Streever 2000), soil organic matter at a restored site would be expected to accumulate slowly over time, following the establishment of vegetation. Indeed, several studies have documented delayed development of soil organic matter compared to reference site conditions (e.g., Lindau and Hossner 1981; Craft et al. 1988a, 1988b, 2002, 2003; Craft 2000; Edwards and Proffitt 2003; Zeug et al. 2007), with soil organic content still not recovering to levels of a natural marsh 30 years postrestoration (Zeug et al. 2007). Benthic infauna densities at restored sites in North Carolina reached equivalency with densities at reference sites between 8 and 15 years post-restoration (Craft et al. 1999, 2003), which has been attributed to the slow development of organic matter content in restored sites (Moy and Levin 1991; Sacco et al. 1994; Broome et al. 2000). Thus, although vegetation may be present within 2 to 5 years postrestoration (Broome et al. 1986; LaSalle et al. 1991; Craft et al. 1999, 2002; Strange et al. 2002; Edwards and Proffitt 2003; Armitage et al. 2014), organic matter and infauna, which collectively form the base of the marsh food web, recover on longer timescales (e.g., Sacco et al. 1994; Craft 2000). In support of this, Minello and Zimmerman (1992) found a significant positive relationship between decapod density and infauna density based on data collected from natural and restored marshes, and attributed the lower abundance of decapods observed at restored sites to a lower abundance of benthic infauna.

Sequential recovery of ecological functions of restored marshes must be considered when trying to discern attraction versus production of fish and crustaceans in an ecosystem. The absence of a discernable trend over time in fish in our meta-analysis, coupled with the fact that fish densities approached reference conditions prior to typical recovery rates for marsh vegetation (see Ebbets et al. 2019), suggest that the sampled nekton may not have been "produced" by the restored marsh, but rather represent local pools of fish in proximate areas. This, in addition to the high variability we observed, may indicate that total fish density is not a strong indicator of restoration success. The absence of trends in our analysis of nekton densities in open-water habitat may also be consistent with this suggestion, with no clear pattern over time for all groups examined. As with fish, this may suggest that the sampled organisms derived from a local/regional pool of proximate organisms rather than being a function of marsh recovery.

While our meta-analysis used density as a comparison between restored and reference sites, we note that this is only one measure of equivalency of restored marsh habitats. Due to the highly mobile nature of nekton, newly created marshes-following the development of the physical structure - are able to attract fish in the first few years after restoration (e.g., Minello and Zimmerman 1992; Minello and Webb 1997). However, there is likely a delay in the ecosystem support for these species, as other functions recover more slowly (Craft et al. 2002, 2003; Strange et al. 2002; Ebbets et al. 2019). Other measures of functional equivalency have been suggested as important indicators of overall ecosystem fisheries support when comparing restored and reference marshes, including growth, mortality, community composition, condition, and food web structure (Minello and Webb 1997; Callaway et al. 2001; La Peyre et al. 2007; Rozas and Minello 2009; Llewellyn and La Peyre 2011). When evaluating these metrics, a number of studies have observed dissimilarity in the nekton community and/or size structure between restored and reference sites (e.g., Thom et al. 2004; La Peyre et al. 2007; Zeug et al. 2007). La Peyre et al. (2007) observed lower fish condition, defined as the ratio of weight to length, for two out of six fish species collected in terraced, restored marsh ponds compared to unterraced, reference marsh ponds. This was attributed to site-specific environmental differences such as water depth and SAV biomass, or differences in soil organic matter (La Peyre et al. 2007). Although daggerblade grass shrimp ( $P$. pugio) were found in similar numbers in reference and restored marshes, their average size was significantly smaller in restored marshes (Minello and Webb 1997). A similar result with respect to size was found for white shrimp (L. setiferus) when comparing restored marsh and reference marsh (Rozas and Minello 2001). Species assemblages - but not overall nekton abundance-were significantly different in restored and reference marsh systems in Louisiana (Thom et al. 2004). Restored marsh terrace edges (sampled in open-water habitat within $1 \mathrm{~m}$ of the marsh edge) supported a higher percentage of pelagic fish and a lower percentage of benthic fish and crustaceans, compared to reference marshes (Bush 2003; Thom et al. 2004). The authors suggest that benthic species may be more dependent on refugia and benthic food sources, and lower abundances of benthic species at terraced sites may be due to lower organic content and prey availability (Thom et al. 2004). Thus, we emphasize the importance of reviewing additional metrics of functional equivalence when assessing the comparative function of restored and reference sites, as density only tells one piece of the story. 
Although the results of our meta-analysis supported the idea that natural and restored sites are not equivalent, and generally reflected results from site-specific studies in the northern GOM, there was also inconsistency in patterns across taxonomic groups and species. Likely drivers of these inconsistencies are several-fold:

1. Nekton density data are inherently highly variable due to variations in season, habitat conditions (e.g., vegetation, soil), other environmental conditions (e.g., temperature, salinity), and annual recruitment. Furthermore, several studies have highlighted the high variation in nekton densities at small spatial scales, such as changes in nekton densities with distance from the marsh edge either into the marsh interior or open water (e.g., Minello and Rozas 2002; Minello et al. 2008), as well as inconsistent patterns of nekton use across regions of the northern GOM (e.g., Rozas et al. 2012; Rozas and Minello 2015). We could not completely account for many of these factors in our analytical approach.

2. Nekton are highly mobile, moving between coastal habitats on smaller timescales, such as hours to days; and migrating across larger geographic ranges on longer timescales, such as months to years. Due to logistical and financial constraints, it is challenging to adequately sample to capture these trends.

3. Low sample sizes, particularly in analyses of nekton densities with age of restored sites, in combination with high variability of nekton data, often result in high variance and difficultly to detect differences across treatments.

There are likely additional sources of error related to our general analytical approach. We note that our analysis of recovery assumes that catch efficiency is constant across sites and time. It is plausible, however, that capture efficiency could differ between restored and reference sites, and could vary systematically with recovery time as restored sites mature. For example, the efficiency of sampling fish could be greater at locations with more poorly developed marsh vegetation, marsh platform, and edge complexity. This could lead to relatively higher estimates of densities at restored sites, which would underestimate the observed difference between restored and reference sites. In addition, in the unpaired analyses, we standardize studies by gear type, season, salinity zone, and habitat type to allow for comparison. While our analyses controlled for these factors to the extent feasible, there were still additional sources of error. For example, while we accounted for season effects by only comparing densities within the same season, recruitment and migration patterns of a species vary at smaller time scales, even as short as a week or two. Lastly, we included both large-scale marsh creation as well as marsh terraces in our pool of restored sites. However, these restored sites vary in scale, substrate type used, and revegetation techniques (e.g., planted vs. natural recolonization), among others. Depending on the techniques used, this could likely affect the recovery trajectories for nekton using the restored habitat. Many of these caveats are inevitable byproducts of meta-analyses that combine data from different, independent sources, such as disparate sites, times, ecological communities, sampling protocols, and restoration techniques.

\section{Implications for Restoration}

Despite challenges inherent in this kind of meta-analysis, our analyses revealed general patterns that reflect the apparent inability of restored marsh sites to support nekton densities that are consistently comparable to those observed at reference sites, especially within the first decade post-restoration. Therefore, even carefully planned and implemented marsh restoration may not consistently result in nekton production similar to that of natural sites. This is particularly true in the earlier years after restoration, during which time baseline ecological functions (e.g., sediment characteristics, organic matter, nutrient composition) must develop to support subsequent phases of ecological recovery (e.g., productivity of benthic infauna, fish, and crustaceans). This sequential recovery of ecological functions also implies that while nekton may be present in the restored site soon after restoration, the production that can be attributed from the newly created marsh may be delayed, following the development of their food supply and other components of ecosystem support.

Patterns and duration of nekton recovery in restored marsh sites vary significantly across sites, underscoring the need to consider site-specific abiotic and biotic factors in restoration planning. This will enhance the probability of successful recovery of ecological function and achievement of restoration goals. To address this, we emphasize the importance of monitoring structural and functional components of a marsh following restoration, including metrics related to sediment characteristics, flooding depth and duration, and additional landscape attributes such as marsh edge. Furthermore, when assessing the functional equivalence of restored marsh sites, we recommend (1) assessing not only total abundance but abundance of particular species that may be slower to respond (e.g., crustaceans); (2) evaluating other metrics of functional equivalence, such as nekton community composition, fish health, growth rates, population age/size structure, and food web structure; (3) conducting nekton sampling on both the marsh surface and open-water habitat; and (4) extending sampling over many years to better understand recovery trajectories. Lastly, we emphasize the importance of selecting appropriate reference and control sites with similar environmental conditions to make appropriate comparisons of functional equivalence and recovery. 
Acknowledgments The authors would like to thank Allison Ebbets, Anthony Berenguel, Ronald Hall, Timothy Meernik, Michael Carney, Sue Visser, and Matthew Rissing for their help in gathering, compiling, and quality checking data for the analysis. We thank Dr. Just Cebrian, Dr. Hui Liu, Heather Ballestero, and Scott Friedman for providing technical insights and support. We also benefited greatly from the helpful comments of Drs. Tom Minello and Jennifer Leo of the NOAA Southeast Fisheries Science Center, Dr. Mary Baker of NOAA's Assessment and Restoration Division, Dr. Tony Marshak of ECS Federal, LLC in support of the NOAA Fisheries Office of Science and Technology, and two anonymous reviewers. We also thank Diane Callow and Erin Miles for their excellent editorial support.

Funding Information This research was funded by a contract from the National Oceanic and Atmospheric Administration (NOAA) to Abt Associates (and predecessor company, Stratus Consulting) for work associated with the Deepwater Horizon oil spill. The scientific results and conclusion of this publication, as well as any views or opinions expressed herein, do not necessarily represent the view of the other natural resource Trustees for the BP/Deepwater Horizon NRDA.

Open Access This article is distributed under the terms of the Creative Commons Attribution 4.0 International License (http:// creativecommons.org/licenses/by/4.0/), which permits unrestricted use, distribution, and reproduction in any medium, provided you give appropriate credit to the original author(s) and the source, provide a link to the Creative Commons license, and indicate if changes were made.

\section{References}

Armitage, A.R., C.-K. Ho, E.N. Madrid, M.T. Bell, and A. Quigg. 2014. The influence of habitat construction technique on the ecological characteristics of a restored brackish marsh. Ecological Engineering 62: 33-42.

Baker, R., B. Fry, L.P. Rozas, and T.J. Minello. 2013. Hydrodynamic regulation of salt marsh contributions to aquatic food webs. Marine Ecology Progress Series 490: 37-52.

Baltz, D.M., C. Rakocinski, and J.W. Fleeger. 1993. Microhabitat use by marsh-edge fishes in a Louisiana estuary. Environmental Biology of Fishes 36 (2): 109-126.

Beck, M.W., K.L. Heck Jr., K.W. Able, D.L. Childers, D.B. Eggleston, B.M. Gillanders, B. Halpern, C.G. Hays, K. Hoshino, T.J. Minello, R.J. Orth, P.F. Sheridan, and M.P. Weinstein. 2001. The identification, conservation, and management of estuarine and marine nurseries for fish and invertebrates. Bioscience 51 (8): 633-641.

Boesch, D.F., and R.E. Turner. 1984. Dependence of fishery species on salt marshes: The role of food and refuge. Estuaries 7 (4A): 460 468.

Boesch, D.F., M.N. Josselyn, A.J. Mehta, J.T. Morris, W.K. Nuttle, C.A. Simenstad, and D.J.P. Swift. 1994. Scientific assessment of coastal wetland loss, restoration and management in Louisiana. Journal of Coastal Research (special issue no. 20): 1-103.

Broome, S.W., E.D. Seneca, and W.W. Woodhouse. 1986. Long-term growth and development of transplants of the salt-marsh grass Spartina alterniflora. Estuaries 9 (1): 63-74.

Broome, S.W., C.B. Craft, and W.A. Toomey Jr. 2000. Soil organic matter (SOM) effects on infaunal community structure in restored and created tidal marshes. In Concepts and controversies in tidal marsh ecology, ed. M.P. Weinstein and D.A. Kreeger, 737-747. Boston, Massachusetts: Kluwer Academic Publishers.

Bush CS (2003) Nekton utilization of restored habitat in a Louisiana marsh. MS Thesis, Louisiana State University.

Callaway, J.C. 2005. The challenge of restoring functioning salt marsh ecosystems. Journal of Coastal Research SI40: 24-36.
Callaway, J.C., G. Sullivan, J.S. Desmond, G.D. Williams, and J.B. Zedler. 2001. Assessment and monitoring. In Handbook for restoring tidal wetlands, ed. J.B. Zedler, 1st ed., 271-335. Boca Raton: CRC Press.

Casella, G., and R.L. Berger. 2002. Statistical inference. Vol. 2. Pacific Grove: Duxbury.

Chambers, J.R. 1992. Coastal degradation and fish population losses. In Stemming the tide of coastal fish habitat loss, ed. R.H. Stroud, 4551. Savannah: National Coalition for Marine Conservation.

Couvillion, B.R., J.A. Barras, G.D. Steyer, W. Sleavin, M. Fischer, H. Beck, N. Trahan, B. Griffin, and D. Heckman. 2011. Land area change in coastal Louisiana from 1932 to 2010. Scientific investigations map 3164, scale 1:265,000, 12 p. pamphlet. U.S. Geological Survey.

CPRA. 2017. Louisiana's comprehensive master plan for a sustainable coast. Draft plan release. Baton Rouge, Louisiana: Coastal Protection and Restoration Authority. http://coastal.la.gov/wpcontent/uploads/2016/08/2017-MP-Book Single Combined 01. 05.2017.pdf.

Craft, C. 2000. Co-development of wetland soils and benthic invertebrate communities following salt marsh creation. Wetlands Ecology and Management 8 (2/3): 197-207.

Craft, C.B., S.W. Broome, and E.D. Seneca. 1988a. Nitrogen, phosphorus and organic carbon pools in natural and transplanted marsh soils. Estuaries 11 (4): 272-280.

Craft, C.B., S.W. Broome, E.D. Seneca, and W.J. Showers. 1988b. Estimating sources of soil organic matter in natural and transplanted estuarine marshes using stable isotopes of carbon and nitrogen. Estuarine, Coastal and Shelf Science 26 (6): 633-641.

Craft, C., J. Reader, J.N. Sacco, and S.W. Broome. 1999. Twenty-five years of ecosystem development of constructed Spartina alterniflora (Loisel) marshes. Ecological Applications 9 (4): 1405 1419.

Craft, C., S. Broome, and C. Campbell. 2002. Fifteen years of vegetation and soil development after brackish-water marsh creation. Restoration Ecology 10 (2): 248-258.

Craft, C., P. Megonigal, S. Broome, J. Stevenson, R. Freese, J. Cornell, L. Zheng, and J. Sacco. 2003. The pace of ecosystem development of constructed Spartina alterniflora marshes. Ecological Applications 13 (5): 1417-1432.

Dahl, T.E., and S.M. Stedman. 2013. Status and trends of wetlands in the coastal watersheds of the conterminous United States, 2004 to 2009. Report to congress. Washington, DC: U.S. Department of the Interior, Fish and Wildlife Service. https://www.fws.gov/wetlands/ Documents/Status-and-Trends-of-Wetlands-In-the-CoastalWatersheds-of-the-Conterminous-US-2004-to-2009.pdf .

Day, J.W., Jr., L.D. Britsch, S.R. Hawes, G.P. Shaffer, D.J. Reed, and D. Cahoon. 2000. Pattern and process of land loss in the Mississippi Delta: A spatial and temporal analysis of wetland habitat change. Estuaries 23 (4): 425-438.

Day, J.W., Jr., D.F. Boesch, E.J. Clairain, G.P. Kemp, S.B. Laska, W.J. Mitsch, K. Orth, H. Mashriqui, D.J. Reed, L. Shabman, C.A. Simenstad, B.J. Streever, R.R. Twilley, C.C. Watson, J.T. Wells, and D.F. Whigham. 2007. Restoration of the Mississippi Delta: Lessons from hurricanes Katrina and Rita. Science 315 (5819): 1679-1684.

DWH NRDA Trustees. 2016. Deepwater Horizon oil spill: Final programmatic damage assessment and restoration plan and final programmatic environmental impact statement. Deepwater Horizon Natural Resource Damage Assessment Trustees. February. http:// www.gulfspillrestoration.noaa.gov/restoration-planning/gulf-plan/.

Ebbets, A.L., D.R. Lane, P. Dixon, T.A. Hollweg, M.T. Huisenga, and J. Gurevitch. 2019. Using meta-analysis to develop evidence-based recovery trajectories of vegetation and soils in restored wetlands in the northern Gulf of Mexico. Estuaries and Coasts. https://doi.org/ 10.1007/s12237-019-00536-y. 
Edwards, K.R., and C.E. Proffitt. 2003. Comparison of wetland structural characteristics between created and natural salt marshes in Southwest Louisiana, USA. Wetlands 23 (2): 344-356.

Enwright, N.M., S.B. Hartley, M.G. Brasher, J.M. Visser, M.K. Mitchell, B.M. Ballard, M.W. Parr, B.R. Couvillion, and B.C. Wilson. 2014. Delineation of marsh types of the Texas Coast from Corpus Christi Bay to the Sabine River in 2010. U.S. Geological Survey Scientific Investigations Report 2014-5110.

Goodman, L.A. 1960. On the exact variance of products. Journal of the American Statistical Association 55 (292): 708-713.

Gulf Coast Ecosystem Restoration Council. 2016. Comprehensive plan update 2016: Restoring the Gulf Coast's ecosystem and economy. https://www.restorethegulf.gov/sites/default/files/CO-PL 20161208_CompPlanUpdate_English.pdf.

Gulf Coast Ecosystem Restoration Task Force. 2011. Gulf of Mexico regional ecosystem restoration strategy. December. http://www. gulfofmexicoalliance.org/pdfs/GulfCoastReport_Full_12-04_5081_final.pdf.

Hollweg, T.A., M.C. Christman, J. Cebrian, B.P. Wallace, S.L. Friedman, H.R. Ballestero, M.T. Huisenga, and K.G. Benson. 2019. Metaanalysis of nekton utilization of coastal habitats in the northern Gulf of Mexico. Estuaries and Coasts. https://doi.org/10.1007/ s12237-019-00633-y.

Kenward, M.G., and J.H. Roger. 1997. Small sample inference for fixed effects from restricted maximum likelihood. Biometrics 53 (3): 983 997.

Kneib, R.T., and S.L. Wagner. 1994. Nekton use of vegetated marsh habitats at different stages of tidal inundation. Marine Ecology Progress Series 106: 227-238.

La Peyre, M.K., and J. Gordon. 2012. Nekton density patterns and hurricane recovery in submerged aquatic vegetation, and along nonvegetated natural and created edge habitats. Estuarine, Coastal and Shelf Science 98: 108-118.

La Peyre, M.K., B. Gossman, and J.A. Nyman. 2007. Assessing functional equivalency of nekton habitat in enhanced habitats: Comparison of terraced and unterraced marsh ponds. Estuaries and Coasts 30 (3): 526-536.

LaSalle, M.W., M.C. Landin, and J.G. Sims. 1991. Evaluation of the flora and fauna of a Spartina alterniflora marsh established on dredged material in Winyah Bay, South Carolina. Wetlands 11 (2): 191-208.

Lellis-Dibble, K.A., K.E. McGlynn, and T.E. Bigford. 2008. Estuarine fish and shellfish species in U.S. commercial and recreational fisheries: Economic value as an incentive to protect and restore estuarine habitat. NOAA technical memorandum NMFS-F/SPO-90. U.S. Department of Commerce, National Oceanic and Atmospheric Administration, National Marine Fisheries Service. November. https://repository.library.noaa.gov/view/noaa/3612.

Lindau, C.W., and L.R. Hossner. 1981. Substrate characterizations of an experimental marsh and three natural marshes. Journal of the American Soil Science Society 45 (6): 1171-1176.

Llewellyn, C., and M. La Peyre. 2011. Evaluating ecological equivalence of created marshes: Comparing structural indicators with stable isotope indicators of blue crab trophic support. Estuaries and Coasts 34 (1): $172-184$

Mace, M.M., III, and L.P. Rozas. 2017. Population dynamics and secondary production of juvenile white shrimp (Litopenaeus setiferus) along an estuarine salinity gradient. Fishery Bulletin 115 (1): 74-88.

McIvor, C.C., and L.P. Rozas. 1996. Direct nekton use of intertidal saltmarsh habitat and linkage with adjacent habitats: A review from the southeastern United States. In Estuarine shores: Evolution, environments and human alterations, ed. K.F. Nordstrom and C.T. Roman, 311-334. New York: Wiley.

Merino, J.H., L.P. Rozas, T.J. Minello, and P.F. Sheridan. 2010. Effects of marsh terracing on nekton abundance at two locations in Galveston Bay, Texas. Wetlands 30 (4): 693-704.
Minello, T.J. 2000. Temporal development of salt marsh value for nekton and epifauna: Utilization of dredged material marshes in Galveston Bay, Texas, USA. Wetlands Ecology and Management 8 (5): 327 341.

Minello, T.J., and L.P. Rozas. 2002. Nekton in Gulf Coast wetlands: Finescale distributions, landscape patterns, and restoration implications. Ecological Applications 12 (2): 441-455.

Minello, T.J., and J.W. Webb. 1997. Use of natural and created Spartina alterniflora salt marshes by fishery species and other aquatic fauna in Galveston Bay, Texas, USA. Marine Ecology Progress Series 151: $165-179$.

Minello, T.J., and R.J. Zimmerman. 1992. Utilization of natural and transplanted Texas salt marshes by fish and decapod crustaceans. Marine Ecology Progress Series 90: 273-285.

Minello, T.J., K.W. Able, M.P. Weinstein, and C.G. Hays. 2003. Salt marshes as nurseries for nekton: Testing hypotheses on density, growth and survival through meta-analysis. Marine Ecology Progress Series 246: 39-59.

Minello, T.J., G.A. Matthews, and P.A. Caldwell. 2008. Population and production estimates for decapod crustaceans in wetlands of Galveston Bay, Texas. Transactions of the American Fisheries Society 137 (1): 129-146.

Minello, T.J., L.P. Rozas, and R. Baker. 2012. Geographic variability in salt marsh flooding patterns may affect nursery value for fishery species. Estuaries and Coasts 35 (2): 501-514.

Moreno-Mateos, D., M.E. Power, F.A. Comin, and R. Yockteng. 2012. Structural and functional loss in restored wetland ecosystems. PLoS Biology 10 (1): e1001247. https://doi.org/10.1371/journal.pbio. 1001247.

Moy, L.D., and L.A. Levin. 1991. Are Spartina marshes a replaceable resource? A functional approach to evaluation of marsh creation efforts. Estuaries 14 (1): 1-16.

NMFS. 2018. Fisheries of the United States, 2017. Current fishery statistics no. 2017. U.S. Department of Commerce, National Oceanic and Atmospheric Administration, National Marine Fisheries Service. September. https://www.fisheries.noaa.gov/resource/document/ fisheries-united-states-2017-report.

Peterson, G.W., and R.E. Turner. 1994. The value of salt marsh edge vs interior as a habitat for fish and decapod crustaceans in a Louisiana tidal marsh. Estuaries 17 (1B): 235-262.

Roth, B.M., K.A. Rose, L.P. Rozas, and T.J. Minello. 2008. Relative influence of habitat fragmentation and inundation on brown shrimp Farfantepenaeus aztecus production in northern Gulf of Mexico salt marshes. Marine Ecology Progress Series 359: 185-202.

Rozas, L.P. 1995. Hydroperiod and its influence on nekton use of the salt marsh: A pulsing ecosystem. Estuaries 18 (4): 579-590.

Rozas, L.P., and T.J. Minello. 1997. Estimating densities of small fishes and decapod crustaceans in shallow estuarine habitats: A review of sampling design with focus on gear selection. Estuaries 20 (1): 199213.

Rozas, L.P., and T.J. Minello. 2001. Marsh terracing as a wetland restoration tool for creating fishery habitat. Wetlands 21 (3): 327-341.

Rozas, L.P., and T.J. Minello. 2007. Restoring coastal habitat using marsh terracing: The effect of cell size on nekton use. Wetlands 27 (3): 595-609.

Rozas, L.P., and T.J. Minello. 2009. Using nekton growth as a metric for assessing habitat restoration by marsh terracing. Marine Ecology Progress Series 394: 179-193.

Rozas, L.P., and T.J. Minello. 2010. Nekton density patterns in tidal ponds and adjacent wetlands related to pond size and salinity. Estuaries and Coasts 33 (3): 652-667.

Rozas, L.P., and T.J. Minello. 2015. Small-scale nekton density and growth patterns across a saltmarsh landscape in Barataria Bay, Louisiana. Estuaries and Coasts 38 (6): 2000-2018. 
Rozas, L.P., and D.J. Reed. 1993. Nekton use of marsh-surface habitats in Louisiana (USA) deltaic salt marshes undergoing submergence. Marine Ecology Progress Series 96: 147-157.

Rozas, L.P., and R.J. Zimmerman. 2000. Small-scale patterns of nekton use among marsh and adjacent shallow nonvegetated areas of the Galveston Bay estuary, Texas (USA). Marine Ecology Progress Series 193: 217-239.

Rozas, L.P., P. Caldwell, and T.J. Minello. 2005. The fishery value of salt marsh restoration projects. Journal of Coastal Research Special Issue 40: 37-50.

Rozas, L.P., T.J. Minello, R.J. Zimmerman, and P. Caldwell. 2007. Nekton populations, long-term wetland loss, and the effect of recent habitat restoration in Galveston Bay, Texas. Marine Ecology Progress Series 344: 119-130.

Rozas, L.P., T.J. Minello, and D.D. Dantin. 2012. Use of shallow lagoon habitats by nekton of the northeastern Gulf of Mexico. Estuaries and Coasts 35 (2): 572-586.

Sacco, J.N., E.D. Seneca, and T.R. Wentworth. 1994. Infaunal community development of artificially established salt marshes in North Carolina. Estuaries 17 (2): 489-500.

Sasser, C.E., J.M. Visser, E. Mouton, J. Linscombe, and S.B. Hartley. 2014. Vegetation types in coastal Louisiana in 2013. U.S. scientific investigations map 3290 .

Strange, E., H. Galbraith, S. Bickel, D. Mills, D. Beltman, and J. Lipton. 2002. Determining ecological equivalence in service-to-service scaling of salt marsh restoration. Environmental Management 29 (2): 290-300.
Streever, W.J. 2000. Spartina alterniflora marshes on dredged material: A critical review of the ongoing debate over success. Wetlands Ecology and Management 8 (5): 295-316.

Thom, C.S.B., M.K.G. La Peyre, and J.A. Nyman. 2004. Evaluation of nekton use and habitat characteristics of restored Louisiana marsh. Ecological Engineering 23 (2): 63-75.

Tummers, B. 2006. DataThief III. http://datathief.org/.

Turner, R.E., and B. Streever. 2002. Approaches to coastal wetland restoration: Northern Gulf of Mexico. The Hague: SPB Academic Publishing.

Visser, J.M., C.E. Sasser, R.H. Chabreck, and R.G. Linscombe. 1998. Marsh vegetation types of the Mississippi River deltaic plain. Estuaries 21 (4B): 818-828.

Visser, J.M., C.E. Sasser, R.H. Chabreck, and R.G. Linscombe. 2000. Marsh vegetation types of the Chenier plain, Louisiana, USA. Estuaries 23 (3): 318-327.

Visser, J.M., C.E. Sasser, R.H. Chabreck, and R.G. Linscombe. 2002. The impact of a severe drought on the vegetation of a subtropical estuary. Estuaries 25 (6A): 1184-1195.

Zedler, J.B. 2000. Progress in wetland restoration ecology. TREE 15 (10): 402-407.

Zedler, J.B., and S. Kercher. 2005. Wetland resources: Status, trends, ecosystem services, and restorability. Annual Review of Environment and Resources 30 (1): 39-74.

Zeug, S.C., V.R. Shervette, D.J. Hoeinghaus, and S.E.I. Davis. 2007. Nekton assemblage structure in natural and created marsh-edge habitats of the Guadalupe estuary, Texas, USA. Estuarine, Coastal and Shelf Science 71 (3-4): 457-466. 